Scholarly Publishing at a Crossroads: Scholarly perspectives on Open Access

\author{
Sarah Rose Fitzgerald, Corresponding author \\ W.E.B. Dubois Library \\ University of Massachusetts, Amherst \\ 154 Hicks Way \\ Amherst, MA 01003 \\ USA \\ sfitzgerald@umass.edu
}

413-577-3407

Zhehan Jiang

Baylor College of Medicine

1 Baylor Plaza,

Houston, TX 77030

USA

jiangzhehan@gmail.com

The authors declare that they have no conflict of interest.

The authors did not receive any funding for this research.

CRediT contributions:

Dr. Fitzgerald - Conceptualization, Formal Analysis, Investigation, Methodology, Visualization, Writing - Original Draft, Writing - Revising and Editing

Dr. Jiang - Conceptualization, Data Curation, Formal Analysis, Methodology, Visualization, Writing - Original Draft 
Scholarly Publishing at a Crossroads 1

\title{
Scholarly Publishing at a Crossroads: Scholarly perspectives on Open Access
}

\author{
Abstract \\ The cost of access to scholarly research creates inequity for readers with varying resources. Open \\ access publishing is an avenue to address this inequity. This research employed a survey of \\ scholars to discover what they know and think about open access. The survey elicited both \\ faculty and doctoral student perspectives. Data were analyzed according to rank and discipline. \\ Although the majority of scholars across disciplines agreed that their work should be freely \\ available to all readers, there were significant differences between disciplines regarding whether \\ scholars had distributed their publications through open access. The survey instrument was \\ examined through Exploratory Factor Analysis.
}

Keywords: open access, scholarly publishing, university faculty, doctoral students, research universities 


\section{Introduction}

Open access (OA) scholarship is the free online availability of research articles for anyone to legally access, use, and share with attribution to the author (Suber, 2012). While scholarly publications behind paywalls are expensive to access for those outside academia and in developing countries, scholars in well-resourced institutions may not be mindful of this issue because these resources are readily available to them through their institutional library subscriptions. Scholars also may not be aware of their options to make their work openly accessible. This study explores scholars' knowledge of open access and their attitudes toward it.

Even in affluent countries, access to knowledge is limited by steep costs. Housewright, et al. (2013) found that about half of the US academics they surveyed often want articles their library does not offer. The 2019 cancelation of subscriptions to scholarly content by the University of California System and others make this topic especially relevant. When even wellresourced institutions are not willing to subscribe to content through major scholarly publishers, academia must explore other options for accessing knowledge.

Open access includes both gold open access delivered by a scholarly journal, often by charging authors or their funders a publication fee, and green open access, driven by the author, by depositing a pre-print or post-print of an article published in a journal in an institutional repository (IR), disciplinary repository, or on the author's website. The discussion around gold open access and the fees associated with it can sometimes cause confusion among scholars who are wary of predatory publishing schemes which also charge publication fees. Research such as Ithaka's US Faculty Survey, (Housewright, et al., 2013) often asks scholars to rate their concern that journals they publish in are freely accessible online, although green open access methods can allow scholars to make their articles freely accessible online independently of the publication 
journal. This study examines perspectives on open access in all forms, rather than concentrating on the gold open access model. It examines awareness among faculty of the different types of open access. The false impression that one must pay an article processing fee in order to make one's work open access can lead to unwarranted negative feelings toward open access.

If scholars are to make socially conscious decisions, they should be aware of their research dissemination options. It is especially important to gauge whether faculty and aspiring faculty are aware of and interested in open access dissemination options, which make their work accessible to people across the world who may benefit from academic research. Examining scholars' awareness can identify gaps in their knowledge and identify challenges and opportunities for open access publication.

\section{Literature}

Open access has multiple benefits. It increases the impact of articles and facilitates data mining of scholarly knowledge (Tennant, et al., 2016). Open access articles are cited more often than articles only available through toll access (Hajjem, et al., 2006). Readers also download and mention open access articles more on social media than toll access articles (Wang, et al., 2015).

Although there are now several ways of making research articles open access, scholars have not adopted the practice widely. Gargouri, et al. (2012) found that only $24 \%$ of articles published between 2005 and 2010 were openly accessible. However, the adoption of open access dissemination varied by discipline. The rates in Math, Earth and Space Science, Psychology, Professional fields, and Social Science were higher, while the rates in Chemistry, Clinical Medicine, Biomedical Research, Heath, Arts, and Humanities were lower. Publishers play a role in the percentage of articles which are made openly accessible. Bjork, et al. (2014) noted that in 
2013, the copyright agreements for only $81 \%$ of articles from the 100 largest publishers allowed for self-archiving. These authors noted that $94 \%$ of all articles in subject repositories were in PMC or arXiv, repositories devoted to life science, physics, and math, indicating that scholars whose work lies outside science and math are not making considerable use of subject repositories. Other fields have not developed the same infrastructure of subject repositories.

Even when scholars do make their work openly accessible, they often overlook the opportunity to deposit it in their institutional repositories. Kim (2010) found in a study of 17 doctoral granting institutions with institutional repositories that $66.7 \%$ of faculty who selfarchived their publications used their personal webpages, $51.5 \%$ used research group websites, $41.7 \%$ used departmental websites, $28.7 \%$ used disciplinary repositories, and $22.7 \%$ used institutional repositories. These choices are far from ideal, as personal and departmental websites are not as good about providing persistent access to articles as institutional and subject repositories that are designed to preserve access to scholarship. Another advantage that repositories offer over personal and departmental websites is that many of them monitor submissions for compliance with copyright agreements. As with other types of open access, institutional repositories tend to see the most participation from scholars in the sciences compared with those in humanities or social sciences (Dubinsky, 2014).

Rodriguez (2014) noted that $67.1 \%$ of the PhD holding US faculty she surveyed reported familiarity with open access. Only $28.2 \%$ of these had published in an OA journal or repository. Gaines (2015) showed that faculty with tenure at the University of Idaho, a Carnegie classified "higher research activity" university (CPR, IUSE, 2018), are more familiar with open access than faculty without tenure. Her study was limited by a sample size of only 54 faculty respondents. Her focus was also on gold OA journals rather than green OA initiatives like institutional 
repositories. The current study shifts the focus in research on faculty opinions of open access away from the emphasis on Gold OA toward a recognition of the important role of Green OA in the changing scholarly publishing ecosystem. It also examines attitudes toward OA in addition to awareness of OA, since there may be multiple reasons for choosing not to make one's scholarship OA.

Several researchers have examined which factors influence faculty decisions to contribute to institutional repositories. Kim (2011) identified altruism, self-archiving culture, concerns about violating copyright, rank, increased citation, and additional effort as factors influencing deposit in institutional repositories. Kim noted that $40.1 \%$ of faculty were not aware of their institution's repositories. Kim also noted that if a faculty member felt the IR made their work more accessible, they were more likely to make deposits into it. Tmava and Miksa (2017) found that for faculty at the University of North Texas, a Carnegie Classified "Highest Research Activity" university (CPR, IUSE, 2018), their willingness to deposit in an institutional repository was explained $24.8 \%$ by altruism and to lesser extents by concerns over plagiarism and the effort of submission. Yang and $\mathrm{Li}$ (2015) found that $40 \%$ of faculty at Texas A \& M University, a "Very High Research Activity" institution (CPR IUSE, 2018), had published their work in an OA publication, and 7\% had deposited work into the university's institutional repository. The most common reason faculty gave for not having deposited work in the institutional repository was lack of awareness of the process. The survey did not ask respondents to identify whether they had made their work open access through a disciplinary repository or a personal website. Yang and Li reported that faculty were not aware that Google and Google Scholar index documents in institutional repositories, which might explain their limited contributions to the repository at their institution. Our survey also tested scholars on their knowledge of IR indexing. 


\section{Conceptual Framework}

Studies of faculty opinions of open access often rely on college affiliations to establish disciplinary classifications. This approach is problematic because scholars from the same college often differ in the paradigms they follow regarding scholarly literature and publication. For example, if the humanities and social sciences are lumped together in a single college, then scholars whose disciplines value monographs highly, such as the humanities (Housewright, et al., 2013), and scholars whose fields prefer research articles, such as the sciences, are lumped together. Another disciplinary difference in perspectives on publication comes from the funding of different disciplines. While STEM fields receive a lot of grant money, which may include provisions for gold open access publication or come with stipulations that the research must be publicly accessible, social science and humanities fields receive fewer and smaller grants and therefore have less financial support and fewer mandates for making their work open access. To create a set of disciplinary categorizations whose members share similar research and publication paradigms, this study relies on Biglan's (1973) categorization of academic disciplines. Scholars were asked to identify themselves as members of "applied science" (such as engineering or medicine), "pure science" (such as biology, physics, or math), "applied social science” (such as education, social work, or business), "pure social science” (such as psychology, anthropology, or sociology), or "humanities" (such as art, English, or philosophy). Using Biglan's distinction between applied and pure disciplines allows for variation in the way these scholars tend to approach scholarly literature. Scholars in applied fields are naturally more interested in dissemination of their work to practitioners. Also, while pure disciplines tend to seek and share information through their disciplinary methodological lenses, applied fields tend to draw on a 
variety of disciplinary lenses to approach their object of study. These differences can impact which publication and dissemination mediums are most relevant to their work.

\section{Methods}

This study employs survey methodology to examine scholarly perspectives on and awareness of open access research dissemination. The authors employed quantitative analysis using descriptive statistics and chi square tests to discover trends in the data as well as an exploratory factor analysis to identify the most valuable questions on the survey instrument for future research.

Though previous research on scholarly perceptions of open access has primarily concentrated on faculty members, this study includes doctoral students as well, in order to gauge the attitudes of the faculty of the future. Doctoral students make publishing decisions before they receive their PhDs, since many of them produce articles as students and collaborate on faculty research projects and they must all decide how to publish their dissertations. Engaging beginning scholars in considering publication options is useful in helping them form good habits and make informed choices in their future publishing careers. Carpenter (2012) found that doctoral students in the UK were not aware of or had misconceptions about what open access is. For instance, many students erroneously thought open access journals were not peer reviewed and many were not sure whether authors could archive journal articles in conventional journals.

Faculty and doctoral students from a public research university were asked to rate their familiarity with and attitudes towards open access publication. The university is classified as showing "Very High Research Activity" by the Carnegie Classification system (CPR IUSE, 2018). The university included 2,009 faculty members and 1,617 doctoral students in fall 2018, 
when the survey was conducted. With the assistance of the Provost's Office and the Graduate School Dean's Office, emails were sent with a link to a Qualtrics survey to all university faculty and doctoral students. The survey contained questions regarding university rank, discipline, knowledge of open access, and opinions of open access. There were also two open-ended questions to allow qualitative responses on open access. After respondents answered whether they understood the difference between gold and green open access, they were given definitions of both to aid them in the completion of the rest of the questions.

The survey yielded 273 respondents ( $8 \%$ response rate). This included 67 respondents from applied sciences, 35 from pure sciences, 78 from applied social sciences, 33 from pure social sciences, and 54 from humanities disciplines. Because we felt scholars were most qualified to define their own discipline, we cannot provide a response rate for respondents by discipline. There were 6 individuals who did not provide a disciplinary identity. The respondents included 128 doctoral students and 137 faculty members (21 non-tenure track, 50 tenure track without tenure, and 66 tenured). The remaining respondents did not identify their role. Although the response rate for doctoral students (8\%) was slightly higher than that for faculty (7\%), we do not observe that the difference compromises the findings from our survey. Findings from the two groups are disaggregated where appropriate. As always with voluntary research, the respondents may have been those who are most passionate for or against the topic, in this case open access research dissemination. Although the web survey format may have decreased our response rate (Fan \& Yan, 2010), it was the only method available to us to reach all faculty and doctoral students at the university. Scholars have many demands on their time, so we expected the majority would not respond to the survey request. We sent reminder emails to potential participants to increase the response rate. 
An exploratory factor analysis was run on the survey data to identify conceptual constructs related to interest in Open Access research dissemination. This analysis will be useful in refining the survey instrument in order to facilitate future surveys on a national or international scale.

\section{Findings}

The overall viewpoint on sharing research publicly was positive. Of respondents, $76 \%$ felt making their work open access would be beneficial for audiences interested in their work. Similarly, $75 \%$ agreed or strongly agreed that their research should be freely available to all readers. Only $6 \%$ disagreed or strongly disagreed with this statement. There were not significant differences between disciplines. In addition, $71 \%$ felt that open access broadens the impact of research. Most, $68 \%$, felt researchers should retain the right to post their articles in a repository when publishing in a journal. A majority, 55\%, felt making their work open access would be beneficial for their career. Only $22 \%$ felt that the traditional scholarly publishing model works well.

Troublingly, 74\% of respondents said they were "not at all familiar" with the difference between gold open access and green open access. This finding was apparent in the open-ended responses, many of which equated all open access with gold open access despite a definition of each appearing in the survey. Of respondents, $71 \%$ were not at all familiar with the SPARC Author Addendum to keep their copyright and $40 \%$ were not at all familiar with Creative Commons Licenses to allow open access. Over $10 \%$ of respondents said they were "not at all familiar" with the concept of open access publication. Most of these were doctoral students, so they may have a chance to learn about open access as they continue their education. A chi square test revealed the association between familiarity with open access and role (doctoral student, 
non-tenure track faculty, tenure track faculty without tenure, and tenured faculty) to be statistically significant, $\mathrm{X}^{2}(6, \mathrm{~N}=264)=16.539, \mathrm{p}<.05$. As shown in Figure 1, respondents from the pure fields were more likely to report familiarity with open access than respondents from the humanities or the applied fields.

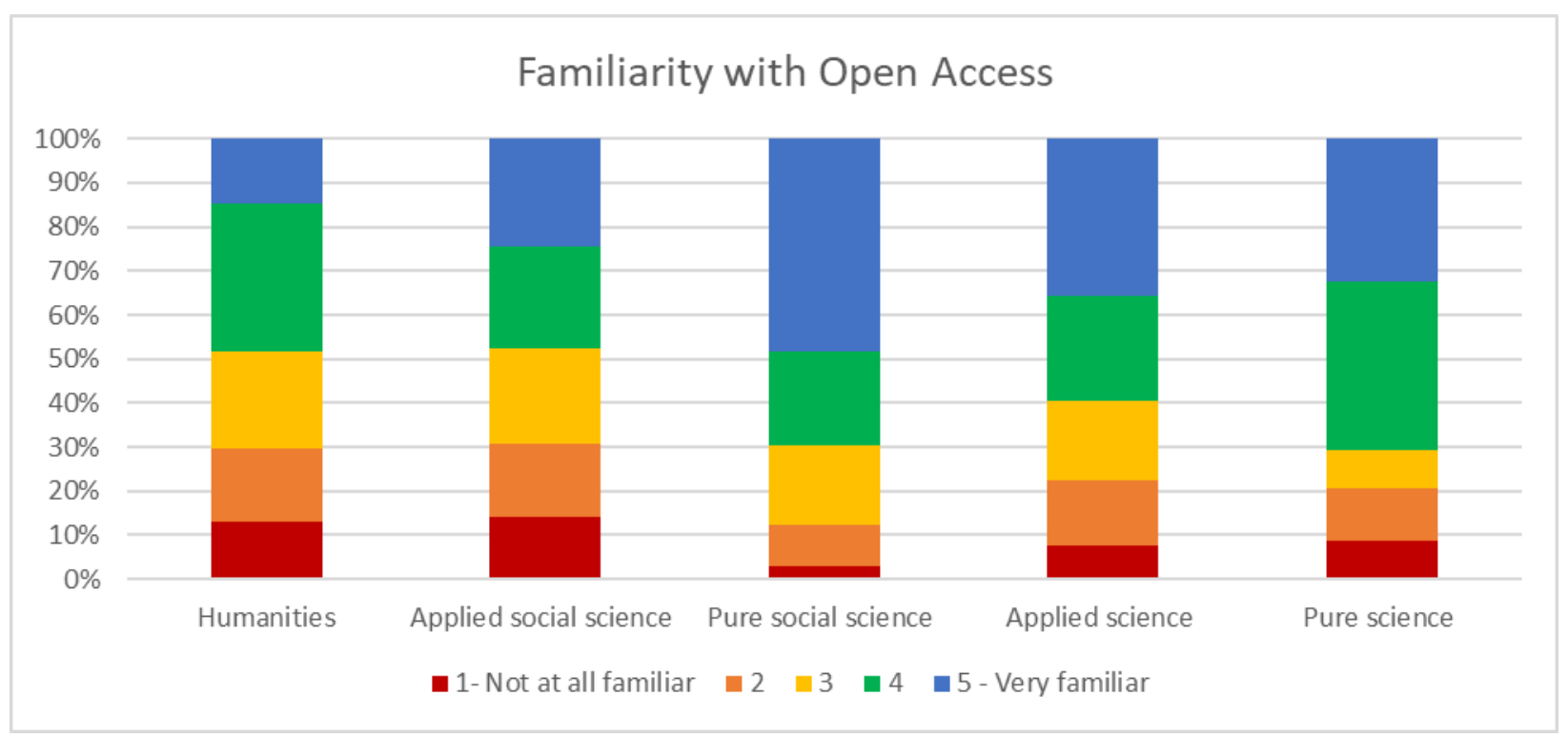

Figure 1. Percentage of scholars by field who reported familiarity with open access.

According to the survey, $33 \%$ of respondents are very familiar with ResearchGate and Academia.edu, but most were not familiar with more reliable forms of green open access such as institutional repositories and disciplinary repositories. Of respondents, 30\% identified Academia.edu or ResearchGate as their ideal outlet to make their work open access, while fewer identified institutional repositories or disciplinary repositories as their ideal outlet. In addition, $47 \%$ reported being "not at all familiar" with disciplinary repositories and $31 \%$ reported being "not at all familiar" with institutional repositories. This finding is particularly problematic because $23 \%$ of respondents expressed concerns about violating copyright agreements, concerns that could be alleviated by working with librarians to make work open access through the 
institutional repository instead of using ResearchGate or Academia.edu. Of respondents, $89 \%$ were interested in having copyright and intellectual property guidance from librarians.

Several of the survey questions elicited a response of "neither agree nor disagree" from a plurality of respondents. This response indicates a lack of knowledge about open access among these scholars. This lack of knowledge was expressed in many of the open-ended responses to the survey as well. Questions to which the most common response was "neither agree nor disagree" included "Research deposited in an institutional repository is accessible through Google and Google Scholar," "If I publish in a subscription publication, I may not make my work open access," and "Research deposited in an institutional repository is freely available to all readers".

Of responding researchers, $44 \%$ agreed or strongly agreed that their work reaches those they wish to reach, and $38 \%$ of researchers were unsure whether their work reaches those they wish to reach. Since most respondents have not made their work open access $(71 \%)$, this finding seems to be at odds with the finding that the majority of respondents $(75 \%)$ feel their research should be freely available to all readers. Likely, while researchers feel their work should be publicly accessible, the stakeholders they most urgently need to reach are those they are already reaching, scholars in their field who are responsible for tenure and promotion evaluation. This explanation is borne out by the finding that $97 \%$ of respondents reported wanting to reach scholars in their field while only $50 \%$ reported wanting to reach the general public. Since the institution studied is a public institution, taxpayer money contributes to its funding, so the university may be considered to have an obligation to make its research accessible. This obligation is strengthened by the university's stated mission, which includes increasing the 
knowledge and social condition of the people of the nation and the world through the dissemination of knowledge.

Only $13 \%$ of respondents had published work through gold open access. Slightly more, $16 \%$, had published work through green open access. Among respondents, $71 \%$ had not published using either open access option. Given that many of the respondents who said they had not made use of either option were doctoral students, some of them may not have published anything yet. A chi square test showed the association between publishing gold OA, green OA, or neither and role (doctoral student, non-tenure track faculty member, tenure track faculty member without tenure, and tenured faculty member) was statistically significant $\mathrm{X}^{2}(6$, $\mathrm{N}=260)=39.317, \mathrm{p}<.001$. Future surveys could differentiate between scholars who have never published and those who have published, but not made their work open access. Gold open access has been participated in among a larger portion of pure scientists than other fields (most likely because of funding opportunities for these scientists). A chi square test showed the association between discipline and publishing gold OA, green OA, or neither was significant $\mathrm{X}^{2}(8$, $\mathrm{N}=262)=16.746, \mathrm{p}<.05$.

Humanities respondents reported the least interest in open access publishing. This is understandable, since the monograph culture of the humanities (Housewright, Schonfeld, \& Wulfson, 2013) does not readily lend itself to current trends in open access opportunities. Fewer grant opportunities in the humanities than the sciences also make Gold OA more challenging, since Article Processing Fees may be more of a barrier to humanists. However, growing pressures to publish articles in the humanities and growing efforts to facilitate open access monograph publishing mean open access is not irrelevant to humanists. 
Of respondents, $45 \%$ said they never save PDF copies of their pre-publication manuscripts to share in open access venues. Only $15 \%$ say they always do. Only $18 \%$ reported negotiating with journal publishers regarding copyright. Nearly half, $48 \%$, of respondents expressed definite interest in making publications available through their institutional repository. Only $6 \%$ said they were definitely not interested in doing so. Unfortunately, $8 \%$ of respondents felt they did not have departmental support for making their work open access.

The open-ended comments often equated all open access with gold open access, despite our efforts to define and differentiate gold open access from green open access in the survey text. Respondents expressed concerns that OA publication would mean a lack of peer review process and a lack of respect from tenure and promotion committees, despite the fact that green open access is compatible with many rigorously reviewed and respected journals.

\section{Exploratory Factor Analysis}

In order to develop an instrument for measuring attitudes toward open access, we began with a correlation analysis to screen out indiscriminative questions, and we conducted an exploratory factor analysis (EFA) on our data. These steps allowed a determination regarding what factors were predictive of a scholar's interest in making scholarship OA. Only complete survey submissions without missing data were used for this part of the analysis, resulting in the inclusion of 256 observations. The pairwise correlation plot of the questions can be seen in Figure 2. The correlation plot shows the extent to which the answers to pairs of questions were correlated with each other. The pairs represented by squares with a darker shade are more highly correlated (either positively or negatively) with one another than pairs represented by squares with lighter shades. Questions with mean correlations lower than 0.2 with other questions were removed prior to the EFA: V10, V17, V19, and V20. The removal, a practice commonly seen in 
the development and validation of an instrument (see Muris, et al., 1998 for example), was performed due to the inconsistencies of the questions that did not contribute useful information to the latent variables of interest. This step serves as an initial screening prior to the modeling.

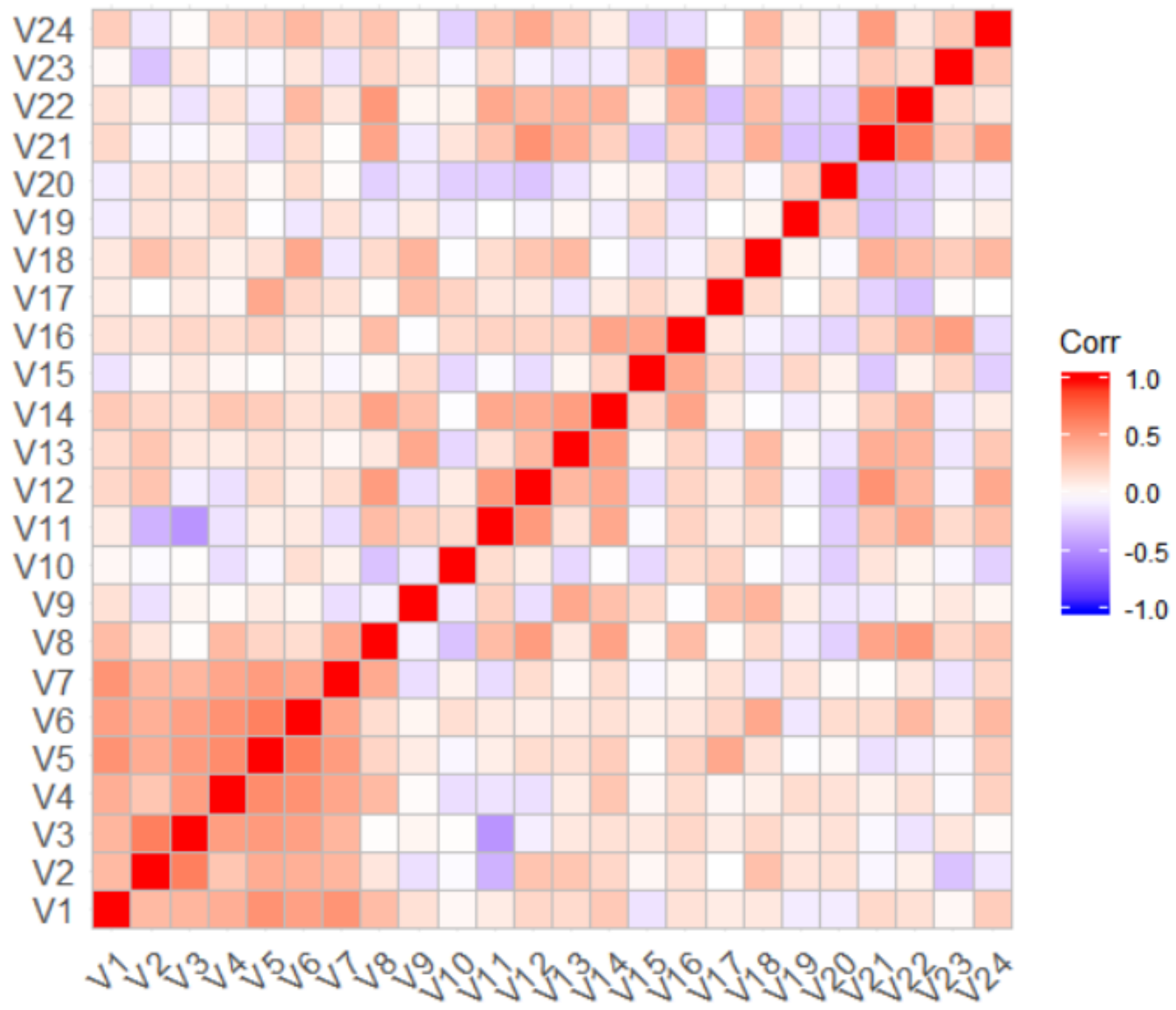

Figure 2. Pairwise correlation plot of survey questions 1-24

After screening the selected questions, a scree plot powered by principal component analysis (PC) and factor analysis (FA) extraction techniques was executed and is displayed in the left panel of Figure 3. These two methods of analysis allow the researchers to determine how 
many factors underlie the data from the 24 questions respondents were asked. According to the practical criterion (Zoski \& Jurs, 1996), PC and FA did not agree with each other in the number of factors underlying the data: PC suggested that there were 3 factors where FA favored 4 factors (i.e., the first point of the line that falls below 1). Due to the uncertainty, we fitted both 3-factor and 4-factor EFA models for further investigation. The EFA configurations were set to align with Hinkin (1998): (1) “oblimin" was selected to perform rotation such that the correlations among the factors were allowed and (2) "ordinary least squared/minres" factoring was used, as it is known to provide results similar to "Maximum Likelihood" without assuming multivariate normal distribution, and derives solutions through iterative Eigen decomposition like principal axis. Note that other options, such as "orthogonal" rotation and "Maximum Likelihood" estimator, although available in many software packages, are not realistic in many settings. On one hand, assuming latent variables independent to each other makes least sense, when they are investigated within the same theoretical framework. On the other hand, the fact that data are often distributed non-normally often introduces biases into modeling outcomes, if an estimator requires strict distributional assumptions. Both 3-factor and 4-factor models yielded poor model fits prior to the second round of the question screening. Questions V1, V2, V9, V13, V14, and V16 were removed, as their factor loadings were lower than 0.3 , showing that the associations between these questions and factors were weak. At this point, V3-8, V11-12, V15, V18, and V21-24 remained.

According to Williams (2011), feeding the remaining data to the 4-factor model resulted in acceptable fits: (1) the root mean square of the residuals (RMSR) was 0.03, (2) the Tucker Lewis Index of factoring reliability (TLI) was 0.965 , and (3) the root mean square error of approximation (RMSEA) was 0.042 and the $90 \%$ confidence intervals were 0.006 to 0.062 . On 
the other hand, the 3-factor model was almost equally good: (1) the RMSR was 0.03, (2) the TLI was 0.959 , and (3) the RMSEA was 0.045 and the $90 \%$ confidence intervals were 0.019 to 0.062. We selected the latter model because (1) the 4-factor model possessed a one-item-factor that is impossible to explain and (2) the parsimonious model should be the winner under the statistical rules.

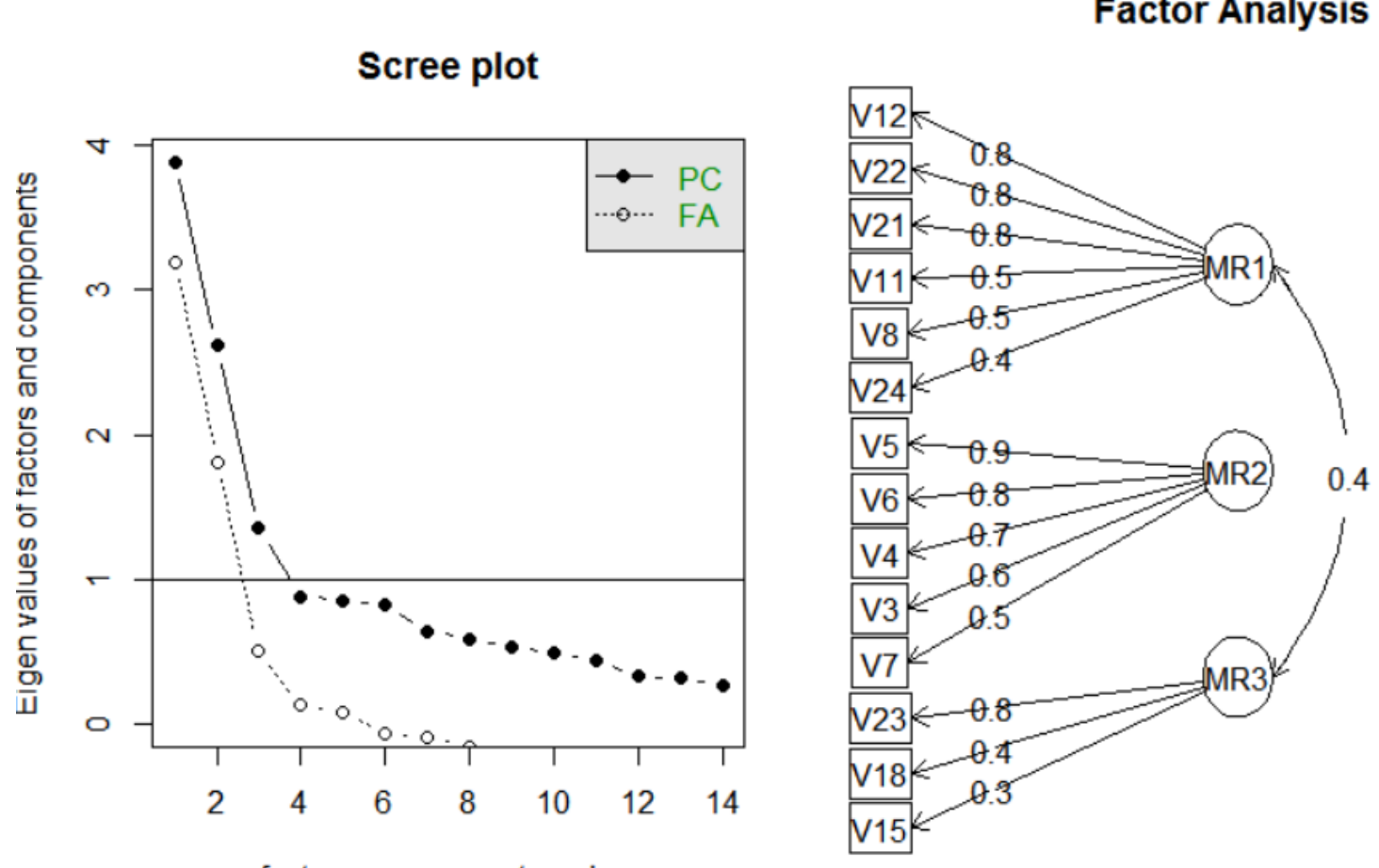

Figure 3. Scree plot and Factor Analysis

We now turn to describing the underlying factors. The first factor, MR1, incorporates questions $8,11,12,21,22$, and 24. These questions asked scholars: Rate your agreement with V8. Open access publishing leads to higher citation rates of articles

V11. My research should be freely available to all readers

V12. Open access broadens the impact of research

V21. Making my work open access is/would be beneficial for my career 
V22. Making my work open access is/would be beneficial for audiences interested in my work

V24. Knowing work will be accessible through Google and Google Scholar when placed in an institutional repository makes me more likely to deposit

These questions all relate to scholars' alignment with the consequences of OA, such as whether scholarship should be more financially accessible and whether OA increases the impact of scholarship, so we name this factor "Attitude toward OA".

The second factor, MR2, incorporates questions 3, 4, 5, 6, and 7. These questions asked scholars: Rate your familiarity with

V3. The Sparc author addendum

V4. Creative commons licenses

V5. Institutional repositories

V6. Disciplinary repositories

V7. ResearchGate or academia.edu

These questions all relate to awareness of options for achieving green open access publication, so we name this factor "Familiarity with OA". Two other questions dealt with familiarity with open access, but we suspect that asking scholars to rate their familiarity with open access publication (V1) was too general to determine meaningful differences in their knowledge and asking scholars to rate their familiarity with the differences between gold and green open access (V2) may have been too dependent on specialized terminology.

The third factor, MR3, incorporates questions 15, 18, and 23. These questions asked scholars: Rate your agreement with 
V15. When I publish in a journal, I negotiate with the publisher regarding the copyright terms

V18. Important researchers in my field make their work open access

V23. I have departmental encouragement to make my work open access

These questions relate to the scholars', disciplines', or departments' participation in the OA movement, so we name this factor "Uptake of OA".

\section{Discussion}

Our finding that $71 \%$ of respondents had not made their work open access aligns with the finding of Gargouri, et al. (2012) that a minority of articles are available open access and Rodriguez's (2014) finding that only $28.2 \%$ of faculty had published in an OA journal or repository. This is a disappointing confirmation, years later in the open access movement. Our findings confirm those of Gargouri et al. that OA participation varies by discipline, but we found that agreement with OA values does not vary significantly with discipline. Our finding that the majority of scholars support OA is heartening, but the challenge becomes how to facilitate a participation rate in OA that matches the level of approval for OA values among scholars.

The findings of this survey highlight the importance of communicating to scholars about the option to make their work open access, particularly the concept of green open access and the advantages of institutional repositories over proprietary research sharing sites. Because our findings show scholars are not familiar with the differences between green and gold open access, educating scholars on their free options to make their work OA could be a step toward increasing participation in OA. Interestingly, although fewer scholars were familiar with green open access than gold, more had published work through green open access than gold. This suggests that green OA has greater appeal despite being less well known. 
Disciplinary and departmental support for OA dissemination is important to generating interest in OA because guidelines around what constitutes a quality tenure or promotion package are related to the departmental attitudes toward the value of disseminating research widely. Departments where alternative metrics beyond journal impact factor are valued in making a case for tenure and promotion are warmer environments for OA. Alternative metrics could include the number of times articles are downloaded or the number of media mentions of a research project, which can be influenced by OA dissemination. A scholar's interest in OA can also be affected by how much knowledge their disciplinary and departmental colleagues have to share about Open Access dissemination. Departments with many longstanding full professors may not have experience with OA dissemination to offer their younger colleagues. On the other hand, the protection of tenure may allow longer standing faculty members to think less about their $\mathrm{CV}$ and more about the potential audiences for their research (Harley, et al., 2010). Librarians may want to concentrate OA outreach on science and social science fields where the publishing norms lend themselves more readily to open access dissemination. Based on the survey results, it is particularly important to bring open access options to the attention of applied social scientists, since open access is less of a norm for dissemination in their disciplines and dissemination of their results could have a large impact because of their orientation toward practice. Asking scholars to save PDFs of their pre-publication manuscripts is a simple task that could make research available sooner and start faculty thinking about socially conscious research dissemination. Many institutional libraries offer opportunities for scholars to learn about open access and copyright options, but they may not take advantage of these opportunities. Strong relationships between the library and the departments could be helpful in encouraging participation in these opportunities. 
The exploratory factor analysis conducted in this study sets up a basis for conducting research on larger scales, nationally or even internationally. Our research was conducted at a public institution in an urban setting in the southern U.S. Subsequent research on this topic should address differences across institutions in perspectives and knowledge of open access options. For instance, does public or private administration of an institution make a difference in the climate for and participation in making scholarship publicly accessible? Does institutional religious affiliation play a part in scholarly views on open access? Are attitudes at rural institutions different from urban institutions? Are there regional differences across the nation?

Future surveys should examine additional questions relating to green and gold open access, since this was an area most scholars reported knowing little about. For instance, it would be interesting to know whether scholars are concerned about the difficulties in ensuring perpetual access to their work through a proprietary hosting site such as ResearchGate or Academia.edu. It could also be beneficial to ask researchers whether they are aware that many toll access publishers allow them to make their work open access through preprints or post-prints.

One remedy for the lack of awareness around green open access among scholars might be to create a national or international repository that could be shared by scholars at many universities. This repository might be promoted more easily than a plethora of individual institutional repositories. It might also appeal more to scholars who tend to identify more with their disciplines than with their institutions (Austin, 1991). Since scholars often change institutions as they earn their doctoral degrees and navigate the academic job market, a centralized repository would prevent their work from being associated with an institution they are no longer affiliated with. Housing a repository through a single organization of libraries could increase consistency in metadata and accessibility for green open access documents and 
diminish duplication of effort across institutions. This centralized repository could also be a helpful option for scholars affiliated with institutions that do not have repositories.

The authors have no conflicts of interest to declare. 


\section{References}

Austin, A. E. (1991). Faculty cultures, faculty values. New Directions for Institutional Research, 1990(68), 61-74. https://doi.org/10.1002/ir.37019906807

Biglan, A. (1973). The characteristics of subject matter in different academic areas. Journal of Applied Psychology, 57(3), 195-203. http://dx.doi.org/10.1037/h0034701

Björk, B.-C., Laakso, M., Welling, P., \& Paetau, P. (2014). Anatomy of green open access. Journal of the Association for Information Science and Technology, 65(2), 237250. https://doi.org/10.1002/asi.22963

Carpenter, J. (2012). Researchers of Tomorrow: The research behaviour of Generation Y doctoral students. Information Services \& Use, 32(1/2), 3-17.

Center for Postsecondary Research, Indiana University School of Education. (2018). Carnegie Classification of Institutions of Higher Education. http://carnegieclassifications.iu.edu

Dubinsky, E. (2014). A current snapshot of institutional repositories: Growth rate, disciplinary content and faculty contributions. Journal of Librarianship and Scholarly Communications, 2(3), 1167. http://dx.doi.org/10.7710/2162-3309.1167

Fan, W., \& Yan, Z. (2010). Factors affecting response rates of the web survey: A systematic review. Computers in Human Behavior, 26(2), 132-139. https://doi.org/10.1016/j.chb.2009.10.015

Gaines, A. M. (2015). From concerned to cautiously optimistic: Assessing faculty perceptions and knowledge of open access in a campus-wide study. Journal of Librarianship \& Scholarly Communication, 3(1), 1-40. https://doi.org/10.7710/2162-3309.1212

Gargouri, Y., Larivière, V., Gingras, Y., Carr, L., \& Harnad, S. (2012). Green and gold open access percentages and growth, by discipline. https://arxiv.org/abs/1206.3664

Harley, D., Acord, S., Earl-Novell, S., Lawrence, S. and King, C. (2010). Assessing the future landscape of scholarly communication: An exploration of faculty values and needs in seven disciplines. Berkeley, CA: Center for Studies in Higher Education. http://escholarship.org/uc/cshe_fsc

Hajjem, C., Harnad, S., \& Gingras, Y. (2006). Ten-Year Cross-Disciplinary Comparison of the Growth of Open Access and How it Increases Research Citation Impact. https://arxiv.org/ftp/cs/papers/0606/0606079.pdf

Hinkin, T. R. (1998). A brief tutorial on the development of measures for use in survey questionnaires. Organizational research methods, 1(1), 104-121. https://doi.org/10.1177/109442819800100106 
Housewright, R., Schonfeld, R. C., \& Wulfson, K. (2013). Ithaka S+R US faculty survey 2012. http://www.sr.ithaka.org/sites/default/files/reports/Ithaka_SR_US_Faculty_Survey_2012 FINAL.pdf

Kim, J. (2010). Faculty self-archiving: Motivations and barriers. Journal of the American Society for Information Science and Technology, 61(9), 1909-1922. https://doi.org/10.1002/asi.21336

Kim, J. (2011). Motivations of faculty self-archiving in institutional repositories. Journal of Academic Librarianship, 37(3), 246-254, https://doi.org/10.1016/j.acalib.2011.02.017

Muris, P., Merckelbach, H., Schmidt, H., \& Mayer, B. (1998). The revised version of the Screen for Child Anxiety Related Emotional Disorders (SCARED-R): Factor structure in normal children. Personality and Individual Differences, 26(1), 99-112. https://doi.org/10.1016/S0191-8869(98)00130-5

Rodriguez, J. E. (2014). Awareness and attitudes about open access publishing: A glance at generational differences. The Journal of Academic Librarianship, 40, 604-610. https://doi.org/10.1016/j.acalib.2014.07.013

Suber, P. (2012). Open access. MIT Press. https://mitpress.mit.edu/sites/default/files/9780262517638_Open_Access_PDF_Version. pdf

Tennant, J. P., Waldner, F., Jacques, D. C., Masuzzo, P., Collister, L. B., \& Hartgerink, C. H. (2016). The academic, economic and societal impacts of Open Access: an evidence-based review. F1000research, 5. https://f1000research.com/articles/5-632/v3

Tmava, A. M., \& Miksa, S. D. (2017). Factors influencing faculty attitudes towards open access institutional repositories. Proceedings of the Association for Information Science and Technology, 54(1), 519-522. https://doi.org/10.1002/pra2.2017.14505401061

Wang, X., Liu, C., Mao, W., \& Fang, Z. (2015). The open access advantage considering citation, article usage and social media attention. Scientometrics, 103(2), 555-564. https://f1000research.com/articles/5-632/v3

Williams, L. J. (2011). Decomposing model fit: Measurement vs. theory in organizational research using latent variables. Journal of Applied Psychology, 96(1), 1. https://doi.org/10.1037/a0020539

Yang, Z. Y. L., \& Li, Y. (2015). University Faculty Awareness and Attitudes towards Open Access Publishing and the Institutional Repository: A case study. Journal of Librarianship and Scholarly Communication, 3(1), 1-29. https://doi.org/10.7710/2162$\underline{3309.1210}$ 
Zoski, K. W., \& Jurs, S. (1996). An objective counterpart to the visual scree test for factor analysis: The standard error scree. Educational and Psychological Measurement, 56(3), 443-451. 


\section{Familiarity with Open Access}

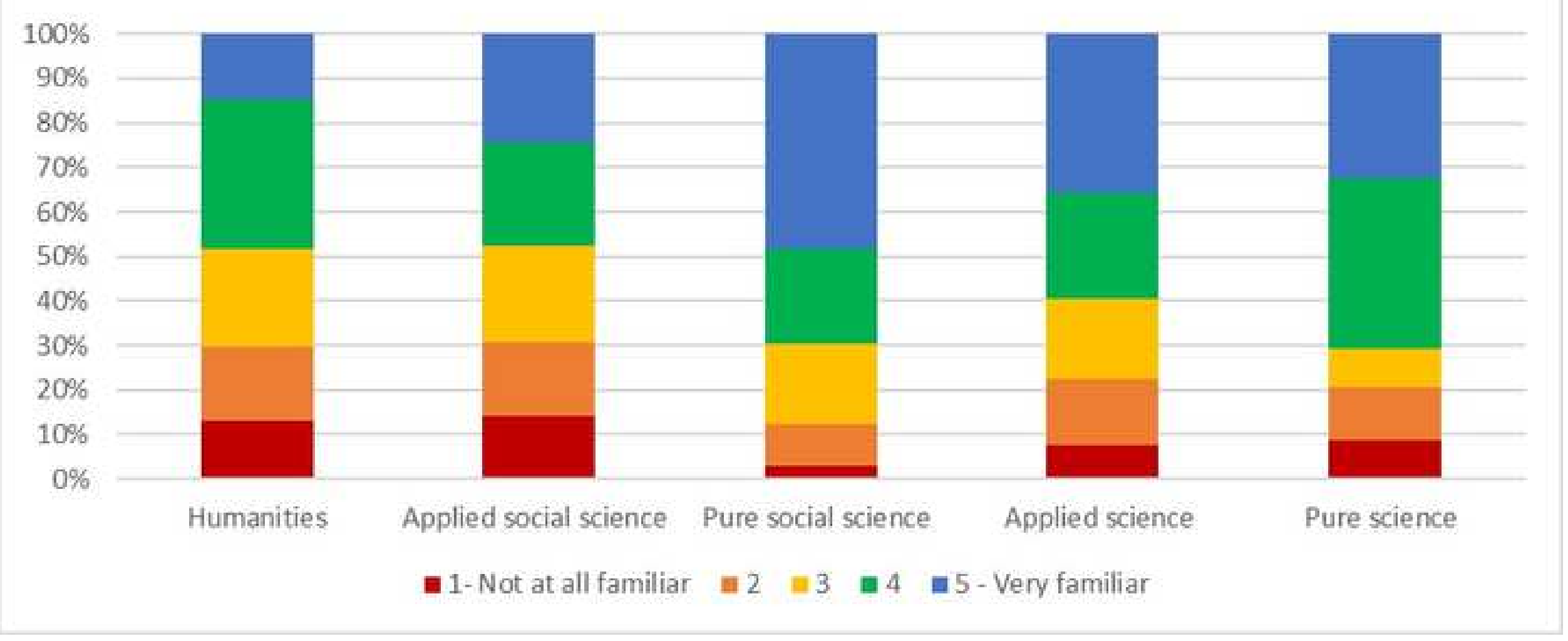




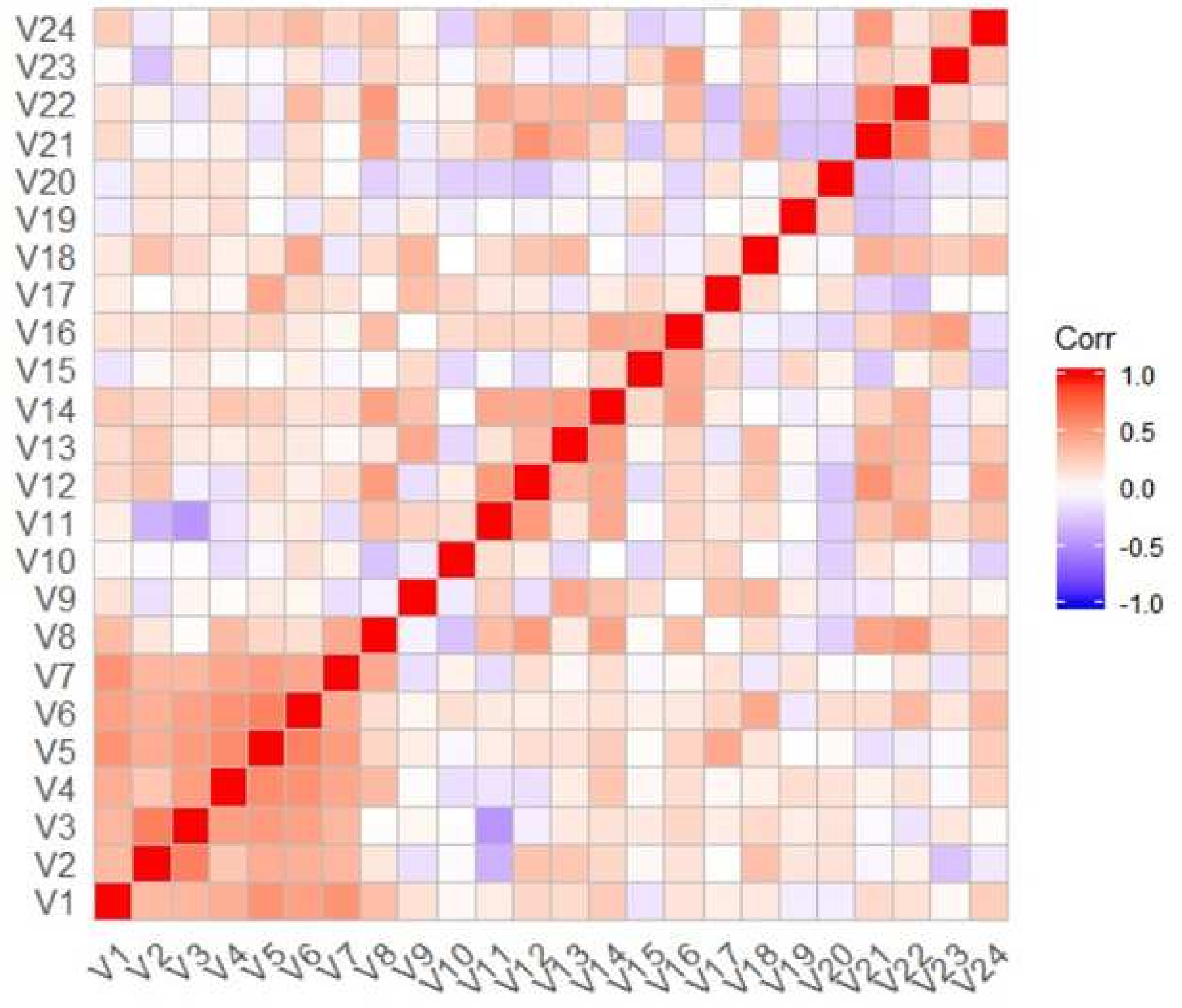




\section{Factor Analysis}

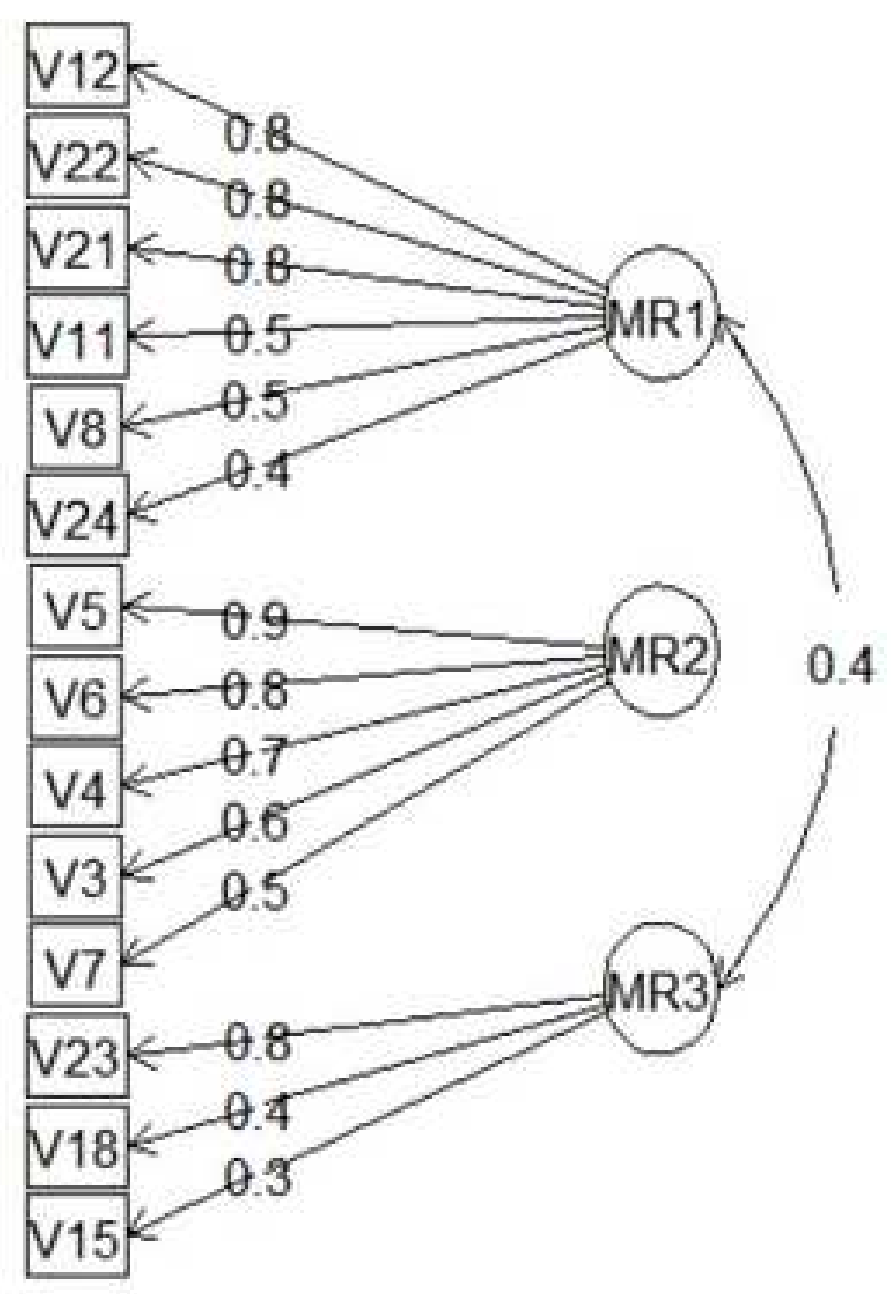

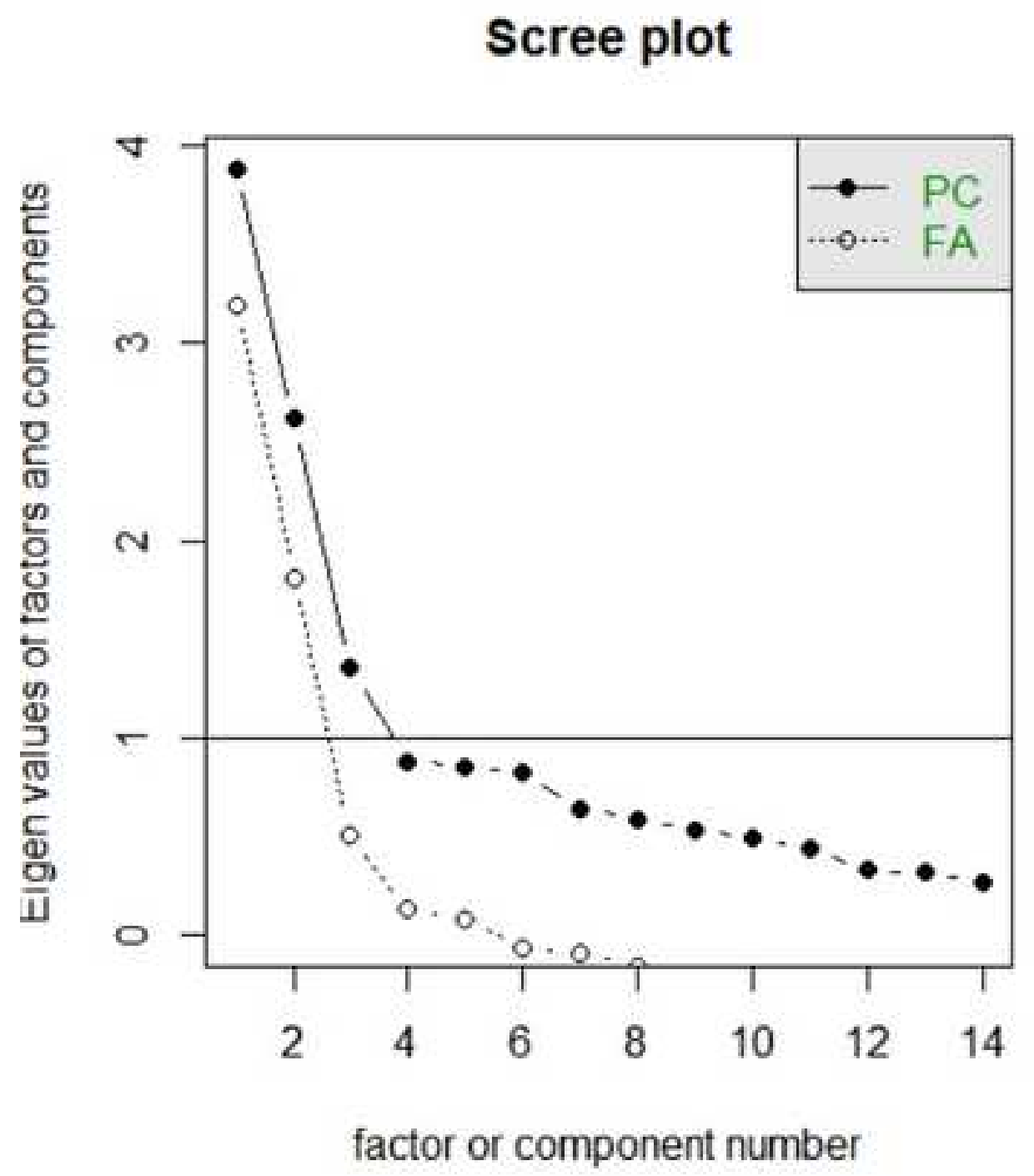

Scree plot 
Response to reviewer:

Thank you for your specific suggestions on our paper.

We have made the grammatical/mechanical edits you suggested.

We have moved the paragraph on participant choice from the theoretical framework section to the methods section

We have added a paragraph to the methods section which specifically names our research design and research goals

We have added several sentences and a citation regarding our response rate.

We added additional explanation for the exploratory factor analysis for readers unfamiliar with quantitative analysis. 